\title{
Transgene expression and fitness of hybrids between GM oilseed rape and Brassica rapa
}

\author{
Henriette AMMITZBøLL, Teis Nørgaard MIKKELSEN and Rikke Bagger JøRGENSEN*
}

Biosystems Department, Ris $\emptyset$ National Laboratory, P.O. Box 49, 4000 Roskilde, Denmark

\begin{abstract}
Oilseed rape (Brassica napus) is sexually compatible with its wild and weedy relative $B$. rapa, and introgression of genes from $B$. napus has been found to occur over a few generations. We simulated the early stages of transgene escape by producing $F_{1}$ hybrids and the first backcross generation between two lines of transgenic $B$. napus and two populations of weedy $B$. rapa. Transgene expression and the fitness of the hybrids were examined under different environmental conditions. Expression of the transgenes was analyzed at the mRNA level by quantitative PCR and found to be stable in the hybrids, regardless of the genetic background and the environment, and equal to the level of transcription in the parental $B$. napus lines. Vigor of the hybrids was measured as the photosynthetic capability; pollen viability and seed set per silique. Photosynthetic capability of first generation hybrids was found to be at the same level, or higher, than that of the parental species, whereas the reproductive fitness was significantly lower. The first backcross generation had a significantly lower photosynthetic capability and reproductive fitness compared to the parental species. This is the first study that examines transgene expression at the mRNA level in transgenic hybrids of $B$. napus of different genetic background exposed to different environmental conditions. The data presented clarify important details of the overall risk assessment of growing transgenic oilseed rape.
\end{abstract}

Keywords: real time PCR / Fv/Fm / $\mathrm{F}_{0}$ / heterosis / biosafety

\section{INTRODUCTION}

The intensified development and regulation of transgenic crops (James, 2004) calls for risk assessment studies to evaluate the consequences of intraspecific and interspecific transgene flow. Genetic engineering enables introduction into ecosystems of genes that confer fitness-related traits. If transgenes spread to wild populations, they have the potential to create or exacerbate weed problems by providing novel traits that allow these plants to compete better, produce more seeds, and become more abundant (Snow, 2002). Information about vigor of transgenic crop-wild hybrids in their natural environment is therefore needed to access the environmental and economic impact of the transgenic crops. It is also important that spontaneous hybrids and introgressed plants can be reliably identified, and that transgene expression in the environment is known. Therefore, we analyzed this in the Brassica crop-weed complex.
Oilseed rape (Brassica napus) is grown for oil production and as feed. In 2004, $19 \%$ of all B. napus grown worldwide was transgenic (James, 2004). One characteristic of oilseed rape is the large dispersal of seed and pollen. For example, a high percentage (5-10\%) of the seeds are shed prior or during harvest (Gulden et al., 2003; Price et al., 1996). The small seeds are easily dispersed by wind and machinery, and feral populations of B. napus occur frequently along roadsides (Chèvre et al., 2004). Pollen of B. napus is dispersed by wind and insects, and has been found up to 3-4 km away from the pollen source (Rieger et al., 2002, Thompson et al., 1999). In addition, $B$. napus can hybridize with at least eight related species, $B$. rapa being the most likely hybridization partner. A high degree of spontaneous hybridization between oilseed rape and the weedy and wild relative $B$. rapa can occur under field conditions (Jørgensen and Andersen, 1994), and

\footnotetext{
* Corresponding author: rikke.bagger.jorgensen@ risoe.dk
} 


\section{H. Ammitzbøll et al.}

there is a well documented possibility of gene exchange between these species (Hansen et al., 2001; Hansen et al., 2003). We used two transgenic B. napus lines to produce the first hybrid generation $\left(\mathrm{F}_{1}\right)$ and the first backcross generation $\left(\mathrm{BC}_{1}\right)$ with two populations of $B$. rapa. The $\mathrm{F}_{1}$ and $\mathrm{BC}_{1}$ plants were grown in several environments, and the potential environmental effects were measured as 1) level of transgene expression, which is assumed to be without costs to plant fitness, 2) seed set as a measure of plant fitness and 3) photosynthetic capability as a physiological estimate of plant fitness.

Identification of transgenic plants at the protein level is quite common; however, transgene expression is not always stable as it can be influenced by environmental conditions such as temperature fluctuations (Down et al., 2001) and periods of heat stress (Broer, 1996; Meyer et al., 1992; Neumann et al., 1997). The environmental effect on the expression of the two transgenes, barnase and barstar, in B. napus $\times$ B. rapa hybrids was analyzed using quantitative PCR. The barnase gene confrers male sterility by preventing pollen production, and the barstar gene restores the fertility of barnase plants by inhibiting the barnase-encoded ribonuclease. The male sterile and fertility restorer lines represent a hybrid system enabling the production of vigorous hybrid seeds (DEFRA 1999; Mariani et al, 1992). Also, the reproductive fitness of the interspecific hybrids was measured. As a potential tool to quantify hybrid vigor, the photochemical capacity of Photosystem II (PSII) was analyzed. A lower photosynthetic rate, in terms of chlorophyll $a$ fluorescence, has been observed to have a negative impact on fitness (Arntz et al., 1998; Arntz et al., 2000). Therefore, chlorophyll fluorescence can be considered a fitness-related parameter. Fluorescence is much simpler to measure than biomass; hence, if the photosynthetic capability reflects the plant vigor, the method would provide a fast alternative in fitness analyses.

Our results clarify the impact of environment and genotype on fitness-related parameters, and we discuss the consequences of our results in respect to the risks of transgene flow from B. napus to populations of B. rapa.

\section{RESULTS}

\section{Expression of the transgenes}

The barnase and barstar genes were transcribed at the same level. Figure 1 shows the expression in barstar plants, and the barnase plants produced corresponding results (data not shown). No significant differences, in
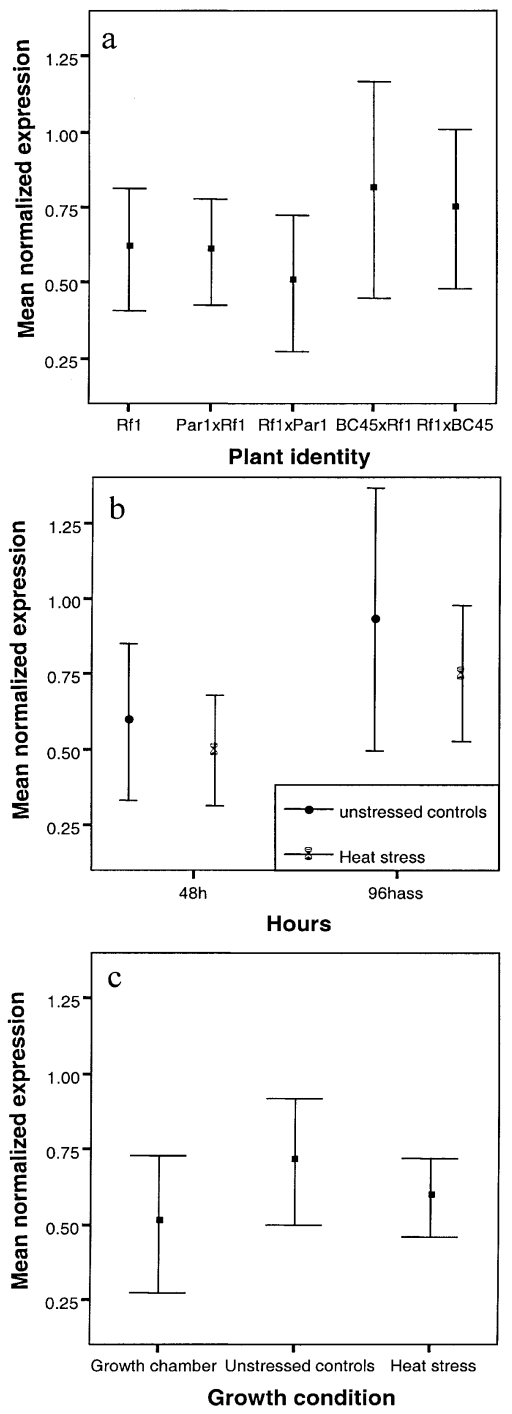

Figure 1. Transgene expression (barstar) in $F_{1}$ hybrids between Brassica napus and B. rapa. Error bar diagrams of mean normalized expression of the transgenes showing the 95\% confidence intervals of: (A) plants of different identity where Rf1 is the transgenic parent, Par $1 \times \mathrm{Rf} 1$ and Rf $1 \times \operatorname{Par} 1$ are the reciprocal $\mathrm{F}_{1}$ hybrids with the Par1 population of $B$. rapa, $\mathrm{BC} 45 \times \mathrm{Rf} 1$ and $\mathrm{Rf} 1 \times \mathrm{BC} 45$ are the reciprocal $\mathrm{F}_{1}$ hybrids with the $\mathrm{BC} 45$ population of $B$. rapa. (B) heatstressed plants and unstressed controls of all genotypes $48 \mathrm{~h}$ after heat-stress and $96 \mathrm{~h}$ after stress stop (96hass). (C) plants of all genotypes grown in growth chamber, as unstressed controls and under heat-stress, respectively.

mean normalized expression, were found between the generations (Tukey tests, $p>0.702$ ), as the $\mathrm{F}_{1}$ hybrids showed the same expression level as the transgenic parent (Fig. 1A). Hybrids from reciprocal crosses showed similar 
expression (Fig. 1A). Also, the $\mathrm{F}_{1}$ hybrids made with different $B$. rapa populations showed the same expression (Fig. 1A). Therefore, for the following analysis, the mean normalized expressions were pooled irrespective of the plant genotype.

The transgene expression during heat stress, as opposed to after heat stress, was found to be similar in all genotypes ( $t$-test, $p=0.072$ ) (Fig. 1B). There was no significant difference between the heat-stressed plants and the unstressed control plants (Fig. 1B). The expression in all three environments was compared, and showed that all genotypes had the same level of transgene expression irrespective of growth conditions (Tukey tests, $p>0.764$ ) (Fig. 1C).

\section{Impact of environmental conditions on plant vigor}

Table 1 shows the mean values and standard deviations of pollen viability and photosynthetic capability for the various genotypes in the different environments. The $\mathrm{BC}_{1}$ hybrids were only grown in the field; hence the environmental effects were not examined for this generation. For most of the analyzed genotypes, the percentage of viable pollen was lowest in the field (pooled $\mathrm{F}_{1}$ mean: $38.4 \%$ ) compared to plants grown under heat stress (pooled $\mathrm{F}_{1}$ mean: $48.3 \%$ ), unstressed controls (pooled $\mathrm{F}_{1}$ mean: $46.8 \%$ ), and in the growth chamber (pooled $\mathrm{F}_{1}$ mean: $47.6 \%$ ).

In most genotypes, the ratio of variable to maximum fluorescence $(\mathrm{Fv} / \mathrm{Fm})$ was significantly lowest in plants grown in the field, and significantly highest in the unstressed plants. Compared to the other environments, plants grown in the field showed large variances, as evident from the standard deviations.

$\mathrm{Fv} / \mathrm{Fm}$ and the basal fluorescence $\left(\mathrm{F}_{0}\right)$, respectively, measured at different time-points during the stay in the conviron cabinets, were similar in hybrids and parental plants. Means based on data from all $\mathrm{F}_{1}$ hybrid genotypes are shown in Figure 2. The heat-stressed plants (Fig. 2A), responded to the heat stress condition by a dramatic decrease in Fm/Fv. After heat stress was ended (96h after stress stop - hass), Fm/Fv rose to a pre-stress level (0h). $\mathrm{F}_{0}$ also decreased during heat stress, and returned to a slightly higher level than the pre-stress level (0h) after stress stop (96hass) (Fig. 2C). The controls responded to the shift in environment by a continuous decrease in Fm/ Fv that did not change significantly upon return to the growth chamber (96hass) (Fig. 2B). $\mathrm{F}_{0}$ increased, and kept rising after return to the growth chamber (Fig. 2D).

\section{Impact of genetic background on plant vigor}

Table 1 shows the mean values and standard deviations of pollen viability, seed set, and photosynthetic capability, for the various genotypes of the different generations.

Impact of transgenes: impact could be studied for those crosses that segregated in transgenic and non-transgenic offspring. Among the male-fertile Non-Transgenic (NT-NMS1) plants and the transgenic male sterile sister plants (NMS1) of all generations, no differences were found in any of the analyzed fitness parameters. The same result was obtained from the transgenic and non-transgenic $\mathrm{BC}_{1}$ hybrids from the Rf1 crosses.

Impact of generation: significant generation differences were found in all analyzed fitness parameters. Parental plants had on average $94 \%$ viable pollen, followed by the $\mathrm{BC}_{1}$ hybrids with a mean of $53 \%$, whereas the $F_{1}$ hybrids had a mean of less than $46 \%$ viable pollen. Parental plants also had significantly more seeds per silique than both hybrids generations, whereas the two hybrid generations produced a similar number of seeds per silique. In the field, the $F_{1}$ hybrids had the significantly highest photosynthetic capability. In the other environments, some $F_{1}$ genotypes showed higher fluorescence than the parents, whereas other genotypes showed fluorescence levels similar to or intermediary to the parents. The $\mathrm{BC}_{1}$ generation had the significantly lowest chlorophyll fluorescence.

Impact of population and cytoplasm: no differences between the two populations of $B$. rapa were found in their pollen viability or in their number of seeds per silique. The chlorophyll fluorescence measurements showed that parental Par1 plants had a slightly higher photosynthetic capability than $\mathrm{BC} 45$ plants. In the hybrid offspring, fluorescence differed between the environments, but no clear trend was found in respect to populations.

In $F_{1}$ hybrids from reciprocal crosses, the pollen viability and the number of seeds per silique did not vary. The chlorophyll fluorescence varied depending on the growth condition, with no clear pattern of consistently higher fluorescence in any particular cytoplasmic background. In the $\mathrm{BC}_{1}$ hybrid generation, no significant responses were found in any of the fitness parameters, irrespective of the populations used as parentals or the cytoplasmic background.

\section{DISCUSSION}

\section{Transgene expression}

Heat stressing temperatures of $35{ }^{\circ} \mathrm{C}-37{ }^{\circ} \mathrm{C}$ have been found to inactivate or reduce transgene expression either 
H. Ammitzbøll et al.

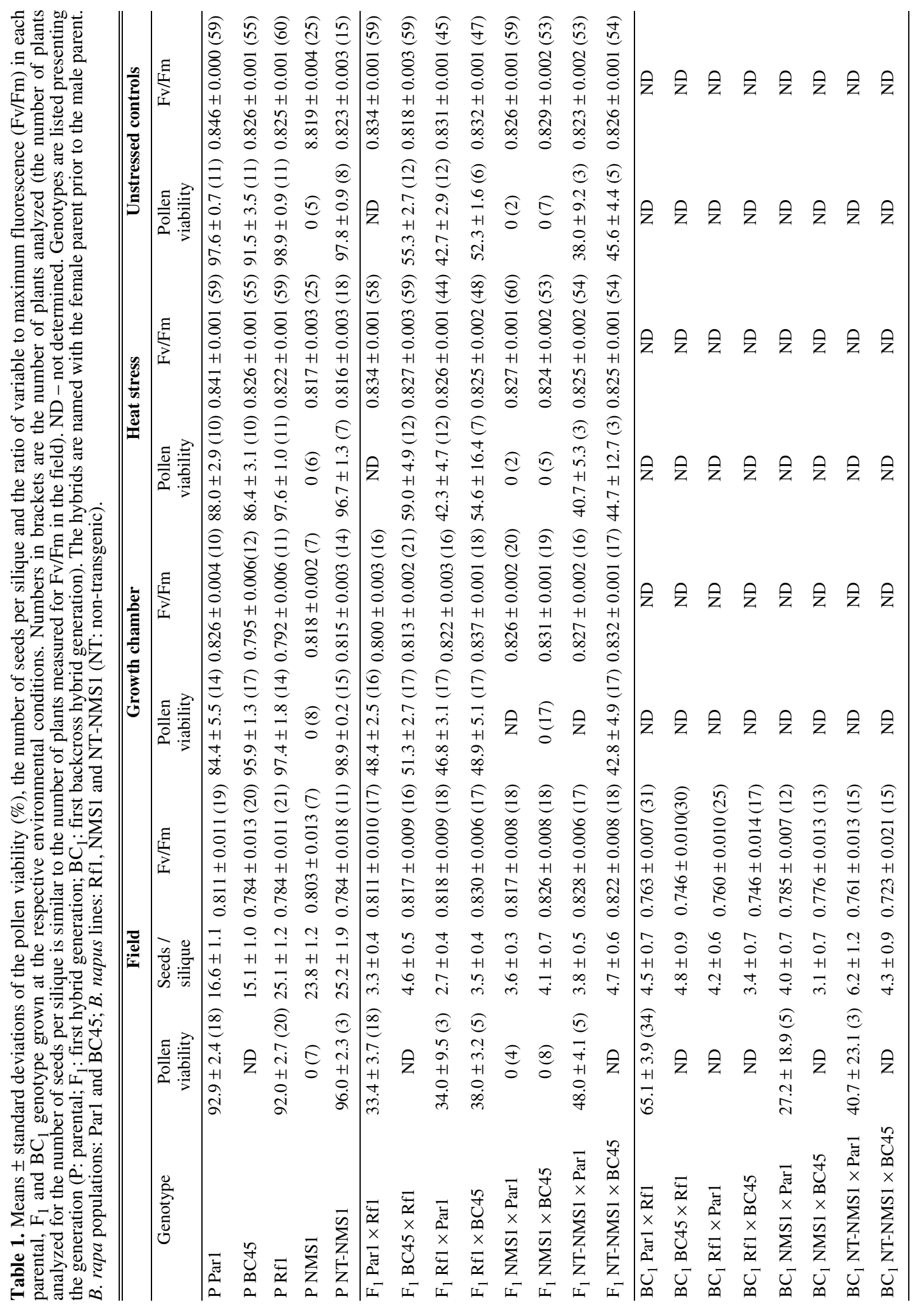




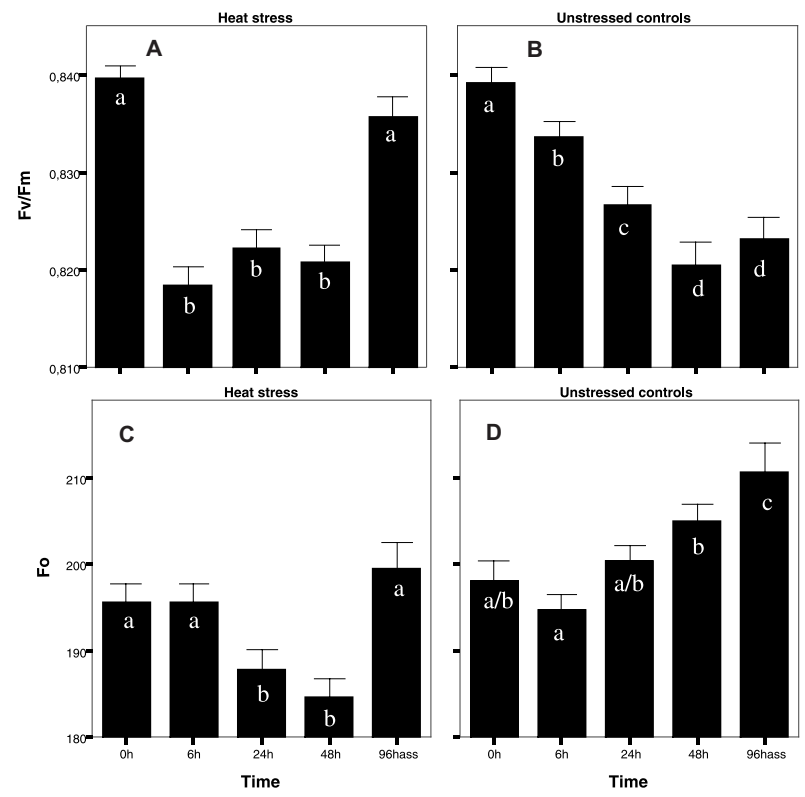

Figure 2. Photosynthetic capability in $F_{1}$ hybrids between Brassica napus and B. rapa. Bar diagram showing mean and $95 \%$ confidence intervals before stress $(0 \mathrm{~h})$, during stress $(6 \mathrm{~h}$, $24 \mathrm{~h}$ and $48 \mathrm{~h}$ ) and $96 \mathrm{~h}$ after stress stop (96hass) in interspecific B. napus $\times$ B. rapa $\mathrm{F}_{1}$ hybrids grown in heat stress or as controls. (A) the ratio of variable to maximum chlorophyll fluorescence $(\mathrm{Fv} / \mathrm{Fm})$ in heat stressed plants; (B) the ratio of variable to maximum chlorophyll fluorescence in unstressed control plants; (C) the basal fluorescence level $\left(\mathrm{F}_{0}\right)$ in heat stressed plants; (D) the basal fluorescence level $\left(\mathrm{F}_{0}\right)$ in unstressed control plants. Statistical differences between the bars within the same subfigure are gives by the letters $a, b, c$ and $d$.

reversibly or irreversibly in transgenic petunia and tobacco (Broer, 1996; Meyer et al., 1992; Neumann et al., 1997). We investigated the stability of transgene expression during heat stress, in two lines of modified B. napus and in their $F_{1}$ hybrids, obtained with two populations of wild B. rapa. Our results show that the examined transgenes were very stably expressed, irrespective of genetic background, cytoplasmic origin and environmental conditions. Similar results have been found at the protein level of $\mathrm{Bt}$ toxin where stable expression in first generation, and backcross progenies $\left(\mathrm{BC}_{1}\right.$ to $\left.\mathrm{BC}_{4}\right)$ of $B$. napus and populations of wild B. rapa, has been shown (Zhu et al., 2004). Our results on the mRNA level of the barnase and barstar transgenes confirm stability, also during heat stress. However, heat stress applied in our experiment was limited to 48h. Some transgenic lines of Arabidopsis thaliana showed silencing after heat treatment at $30{ }^{\circ} \mathrm{C} / 4{ }^{\circ} \mathrm{C}$ for 14 days (Meza et al., 2001). Hence, a longer period of stress might affect transgene expression. Stable expres- sion of transgenes that are introgressed to wild relatives makes risk assessments and post-release monitoring more reliable and straightforward. Similar expression studies of introgressed transgenes in other species and environments are necessary to elucidate if the stable transgene expression that we found in the B. napus $\times$ B. rapa hybrids is a general phenomenon of lines that are selected for marketing.

\section{Impact of the environmental conditions on plant vigor}

Heat stress has been found to have severe detrimental effects on the percentage of viable pollen, the silique and seed production, and the dry matter accumulation in $B$. napus (Angadi et al., 2000; Morrison, 1993; Young et al., 2004). In our experiment, the majority of the parental plants and $\mathrm{F}_{1}$ hybrids responded by producing less viable pollen when exposed to heat stress, but also under field conditions. This effect from field conditions on pollen viability is a new observation that confirms that plants are often more stressed when grown under natural conditions compared to growth chamber conditions.

The relationship between photosynthetic rate and fitness has been investigated in a wild-type Amaranthus hybridus and a mutant with a lower efficiency of electron transport through PSII (Arntz et al., 2000). The mutant had a lower rate of photosynthetic carbon assimilation that could translate into a $10-35 \%$ lower rate of photosynthesis. It was found that the mutant type had lower fecundity and a lowered seedling survivorship (Arntz et al., 2000), implying that a lower photosynthetic rate has a negative impact on fitness. We assume that the same relationship between a decline in $\mathrm{Fv} / \mathrm{Fm}$ and a lower fitness was valid in our experiment; however, we did not investigate if this assumption was correct. We found decreases in Fv/Fm suggesting that the plants grown in the field were exposed to stress. Our results support previous findings in Arabidopsis thaliana where reductions in chlorophyll fluorescence were found when plants were grown in the field as opposed to in a growth chamber (Külheim et al., 2002).

We compared $\mathrm{Fv} / \mathrm{Fm}$ and $\mathrm{F}_{0}$ during and after heatstress. Unexpectedly, Fv/Fm fell continuously in the control plants. This could be a response to the different light conditions in the growth cabinet as opposed to the growth chamber, even though the irradiance did not reach levels that ought to be stressful. $\mathrm{F}_{0}$ increased in our control plants - a response that is normally characteristic to environmental stress (Krause and Weis, 1984). Hence, the symptoms of a stress-response were present in the supposedly unstressed control plants. This complicates 


\section{H. Ammitzbøll et al.}

Table 2. Estimate of fitness parameters of $\mathrm{F}_{1}$ and $\mathrm{BC}_{1}$ hybrids from crosses between $B$. napus and B. rapa relative to $B$. rapa. Estimates are based on present and previous studies.

\begin{tabular}{lcccl}
\hline \hline \multicolumn{1}{c}{ Parameter } & B. rapa & F $_{\mathbf{1}}$ hybrids & $\mathbf{B C}_{\mathbf{1}}$ hybrids & \multicolumn{1}{c}{ References } \\
\hline Survival & 1 & 0.925 & 0.953 & Hauser et al., 1998a, b \\
Fv/Fm & 1 & 1.029 & 0.950 & Present study \\
Pollen viability & 1 & 0.409 & 0.473 & Present study \\
Total number of seeds per plant & 1 & 0.783 & 0.202 & Hauser et al., 1998a*, b*; Present study** \\
\hline Average & 1 & 0.786 & 0.644 & \\
\hline * Number of pods per plant. & & & & \\
** Number of seeds per pod. & & & &
\end{tabular}

analysis of the response in the heat stressed plants where a dramatic fall in $\mathrm{Fv} / \mathrm{Fm}$ was observed. In contrast to previous findings (Havaux, 1993; Krause and Weis, 1984; Yamane et al., 1997), $\mathrm{F}_{0}$ decreased in our heat-stressed plants. Such a decrease has been observed in Vicia faba and Spinacia oleracia (Misra et al., 2001), when high temperature was applied together with high irradiance. Since our control plants responded with a rise in $\mathrm{F}_{0}$, it seems reasonable to believe that the heat-stressed plants experienced both a temperature and an unintended light stress. Using chlorophyll fluorescence in stressed plants as an expression of vigor may not provide straightforward results, as the method is very sensitive to any change in the environment. Also, since plants readily acclimate to alterations in the environment, the results may reflect acclimatization responses that are not representative of the general physiological fitness. In the field, rapid acclimatization processes are known to efficiently adjust the thermostability of PSII in response to various environmental stimuli such as water stress and light (Havaux, 1993). A low Fv/Fm may be an advantage in some situations if it serves to protect the plant on a longterm perspective. Therefore, other parameters such as biomass measurements should be included in examinations of plant vigor despite the intensive labor such measurements require.

\section{Impact of genetic background on plant vigor}

Transgenic plants were just as fit as their non-transgenic siblings in pollen viability, seeds produced per silique and photosynthetic capability. This supports findings from other fitness-related parameters when comparing transgenic and non-transgenic hybrids of B. napus and B. rapa. Previously, no significant differences in survival or the number of seeds per plants has been found (Snow et al., 1999). Together these findings indicate that costs associated with these transgenes are negligible.

No clear effect of cytoplasmic origin or parental population could be observed from our experiments.
Effects from different generations on pollen viability and seed production showed that the parental generation was most fit followed by the $\mathrm{BC}_{1}$ generation and then the $\mathrm{F}_{1}$ generation. This is in agreement with previous findings in hybrid generations between $B$. napus and B. rapa (Hauser et al., 1998b; Snow et al., 1999). This also agrees with the observation that in both plants and animals, hybrids with genotypes more similar to one or the other parental have a higher fitness compared to genetically intermediate hybrids, such as $F_{1}$ hybrids (Arnold and Hodges, 1995). However, our findings on the reproductive fitness are in contrast to our chlorophyll fluorescence measurement, where some $F_{1}$ hybrids had the most efficient photosynthetic capability, followed by the parental generation and then the $\mathrm{BC}_{1}$ hybrids. Heterosis, a fitness boost due to hybridization can result in extreme characteristics in first generation hybrids (Arnold, 1997; Ellstrand, 2003; Rieseberg, 1997), and may be the reason for the observed increases in photosynthetic capability of the $\mathrm{F}_{1}$ hybrids. Hence, the different fitness-related parameters used in our experiments provided opposite directed results as to the vigor of the plant generations.

An attempt to estimate the compounded fitness of the $\mathrm{F}_{1}$ and $\mathrm{BC}_{1}$ hybrids compared to $B$. rapa - based on published data and the present data - is shown in Table 2. The data implies, that since $\mathrm{F}_{1}$ hybrids produce more silique per plant than $\mathrm{BC}_{1}$ hybrids $\left(\mathrm{F}_{1}\right.$ hybrids: 993 silique per plant; $\mathrm{BC}_{1}$ hybrids: 225 silique per plant (Hauser et al., $1998 \mathrm{a}, \mathrm{b})$ ), the total number of seed set per $\mathrm{F}_{1}$ hybrid plant by far exceeds the total number of seed set per $\mathrm{BC}_{1}$ hybrid, as both $\mathrm{F}_{1}$ and $\mathrm{BC}_{1}$ produce the same number of seeds per silique (Tab. 1). When averaging the values included in Table 2, both generations of hybrids have a lower vigor than $B$. rapa, and $\mathrm{F}_{1}$ hybrids have a higher vigor than $\mathrm{BC}_{1}$ hybrids. Other fitness parameters than the ones presented in the table, for example seed viability, could influence the compounded fitness values. Different environmental conditions might also affect the estimated values; hence, it is difficult to give precise estimates. 


\section{Conclusion}

Investigations of two transgenes showed that transgene expression was stable, and being transgenic or not had no impact on fitness. Therefore, weediness or invasiveness is not likely to increase under non-selective conditions. Photosynthetic capability in $\mathrm{F}_{1}$ hybrids of $B$. napus $\times B$. rapa was sometimes higher than their parents, however, their reproductive fitness was lower. The higher photosynthetic capability suggests that $F_{1}$ hybrids may have enhanced vegetative vigor compared to their parents, and may present a larger potential for transgene spread than formerly expected. The compounded fitness estimate suggests a high seed set per $\mathrm{F}_{1}$ plant, and spontaneous introgression of genes from $B$. napus $\times$ B. rapa hybrids to wild species has been reported (Hansen et al., 2001; Hansen et al., 2003). $\mathrm{BC}_{1}$ hybrids form the next step of transgene introgression into wild species, but our results suggest that the vegetative vigor of the $\mathrm{BC}_{1}$ plants is limited. In conclusion, we can recommend that compounded fitness estimates be used in risk assessments of GM plants, as different fitness factors often give different trends. Therefore, the combination of more factors in a compounded estimate has its benefits, and here the photosynthetic capability could be a valuable parameter indicating the vegetative fitness. Our results also showed that the fitness of both parents and hybrids are generally lower in the field, compared to a growth chamber. This is worth considering if risk assessment studies are made under non-natural conditions.

\section{MATERIALS AND METHODS}

\section{Plant materials}

Two transgenic B. napus ssp. oleifera (DC.) lines of the variety "Drakkar" were used (provided by Plant Genetic Systems, Belgium). The "Nuclear Male Sterility" line (NMS1) expresses the ribonuclease barnase, as a hemizygous trait, so that half the offspring are NonTransgenic NMS1 (NT-NMS1) siblings that were used as controls. The homozygous B. napus "Restorer of fertility" line (Rf1) expresses barstar, which restores the fertility in hybrids between NMS1 and Rf1 by specific inhibition of the barnase (Mariani et al. 1990). A promoter that limits their expression to the tapetum cells of the pollen sac during anther development directs both transgenes. Both transgenic lines contain the bar transgene encoding a phosphinothricin acetyl transferase making the plants resistant to phosphinothricin-based herbicides. The bar gene was inserted in the same construct as the barnase and barstar genes. The two transgenic B. napus lines were used to produce $\mathrm{F}_{1}$ and $\mathrm{BC}_{1}$ hybrids with two Danish populations of wild B. rapa ssp. campestris (L.); Par1 (Snow et al., 1999) and BC45 (Landbo and Jørgensen, 1997). For the $F_{1}$ generation, pair-wise crosses were made by hand pollination using 12 NMS1 plants and six $B$. rapa plants of each of the two populations. To analyze the impact of cytoplasmic origin, reciprocal crosses were made with the Rf1 line using $12 \mathrm{Rf} 1$ and six B. rapa plants of each of the two wild populations. For the production of the $\mathrm{BC}_{1}$ generation, $12 \mathrm{~B}$. rapa plants were pair-wise pollinated by six $F_{1}$ hybrids from each of the reciprocal crosses between Rf1 and Par1 or BC45, respectively. Likewise, pair-wise pollinations of $12 \mathrm{~F}_{1}$ male-sterile hybrids with six Par1 plants, and six BC45 plants, were performed. A Basta dot-test was performed on all hybrid plants to validate expression of the transgene encoded herbicide resistance trait. For the cross with the hemizygous NMS1 line, the Basta dot-test was also used to identify the transgenic male-sterile hybrids from their non-transgenic siblings.

\section{Growth conditions}

Table 1 gives the four different environments, the genotypes, and the number of plants grown in the different environments. Seedlings were grown in a growth chamber (16h light $/ 18^{\circ} \mathrm{C}, 8 \mathrm{~h}$ dark $\left./ 16^{\circ} \mathrm{C}\right)$, with both natural and artificial light $(\sim 400 \mu \mathrm{mol})$, until initiation of flowering. Plants were kept in the growth chamber until seeds were collected. For heat stress treatment, $\mathrm{F}_{1}$ and parental plants were moved from the growth chamber to a conviron growth cabinet $\left(16 \mathrm{~h} \mathrm{light} / 37^{\circ} \mathrm{C}, 8 \mathrm{~h}\right.$ dark $/ 20^{\circ} \mathrm{C}$ ) for $48 \mathrm{~h}$, and after heat-treatment they were moved back to the growth chamber. Since the light and air circulation was somewhat different in the conviron cabinets compared to the growth chamber, control plants were moved to a conviron cabinet without heat treatment $(48 \mathrm{~h} ; 16 \mathrm{~h} \mathrm{light} \mathrm{/}$ $18{ }^{\circ} \mathrm{C}$, 8h dark $/ 16^{\circ} \mathrm{C}$ ) during the same period as heat stress was performed. In the conviron cabinets there was only artificial light. Light intensities were; top-leaves: 600-700 $\mu \mathrm{mol}$; mid-leaves: 430-450 $\mu \mathrm{mol}$; basal-leaves: $350 \mu \mathrm{mol}$. For the field experiment, seedlings were transplanted from the growth chamber to the field at the two-leaf stage, and Basta dot-tests performed. Plants were placed in the field in early April and watered when needed. The plants were left to random pollination.

\section{Transgene expression}

An equal volume of the smallest flower buds was collected from each plant $48 \mathrm{~h}$ after initiation of heat-stress, and also 


\section{H. Ammitzbøll et al.}

from corresponding control plants and plants in growth chamber conditions. Thereafter all plants were returned to the growth chamber. Flower buds were collected again from all plants $96 \mathrm{~h}$ after the heat-stress period had ended. The flower buds were kept at $-80{ }^{\circ} \mathrm{C}$ until RNA purification. The buds were homogenized in a Mixer Mill (MM300, Retsch) after freezing in liquid nitrogen, and mRNA was isolated from crude lysate using Dynabeads ${ }^{\circledR}$ mRNA Purification Kit. RT-PCR was made using the Superscript ${ }^{\mathrm{TM}}$ II RNase $\mathrm{H}^{-}$Reverse Transcriptase protocol (Invitrogen). Expression of the transgenes was analyzed on a RotorGene 2000 Real-Time cycler (Corbett Research), initial denaturing $98^{\circ} \mathrm{C}, 180 \mathrm{~s}-40$ cycles: $98{ }^{\circ} \mathrm{C}, 20 \mathrm{~s} ; 58{ }^{\circ} \mathrm{C}, 30 \mathrm{~s} ; 72{ }^{\circ} \mathrm{C}, 30 \mathrm{~s}$; acquiring at $88^{\circ} \mathrm{C}$, $20 \mathrm{~s}$ - hold: $50{ }^{\circ} \mathrm{C}, 30 \mathrm{~s}-$ melt: $50{ }^{\circ} \mathrm{C}-99^{\circ} \mathrm{C}$ rising by $1{ }^{\circ} \mathrm{C}$ each step, hold for $15 \mathrm{~s}$ on first step, then $5 \mathrm{~s}$ on each step afterwards. Sequence-specific primers were designed for actin (forward: 5'-TGACATTAAAGAGAAGCTTG-3'; reverse: 5'-CACTTCATGATGGAGTTGT-3'), which was used as an internal standard, and for barstar and barnase amplification (sequence information is confidential). The mean normalized expression (Muller et al., 2002), as calculated by averaging three concomitant threshold cycle values of the target gene and of the reference gene, respectively, was found using the Q-gene tool (Muller et al., 2002). The actin used as internal standard was similar to the $A$. thaliana actin $2 / 7$ according to a BLAST search. Expression of the actin standard was stable during heat treatment ( $t$-test, $p=0.305$ ).

\section{Pollen viability and seed set}

Pollen from two flowers per plant was collected from parental plants, $\mathrm{F}_{1}$ hybrids and $\mathrm{BC}_{1}$ hybrids (see Tab. 1 for distribution between genotypes). The pollen grains were stained with cotton blue. The percentage of viable pollen grains was determined by finding the ratio of viable to non-viable pollen grains from 200 pollen grains per plant.

The seed set was only measured in plants grown in the field, where pollinators were present. Siliques were collected at maturity from parental plants, $\mathrm{F}_{1}$ hybrids and $\mathrm{BC}_{1}$ hybrids (see Tab. 1 for distribution between genotypes). The number of seeds per silique was determined by collecting 20 siliques from each plant.

\section{Chlorophyll fluorescence}

The chlorophyll $a$ fluorescence was measured using a Plant Efficiency Analyzer (Handy PEA, Hansatech Instruments Ltd., UK), applying one light flash for one second. The leaves were dark-adapted for 20 minutes before measuring. Three leaves of each plant were measured, one at the base, one halfway up the stem, and one at the top, respectively. These measurements were pooled when analyzing the different genotypes. In the field experiment, measurement on only one leaf (halfway up) per plant was made. Chlorophyll fluorescence was measured just before opening of the first flower buds when all plants were still in the growth chamber (0h). Measurements were then taken $6 \mathrm{~h}, 24 \mathrm{~h}$ and $48 \mathrm{~h}$ after moving the plants to the heat-stress or control conviron cabinets. After returning the plants to the growth chamber, measurements were taken $96 \mathrm{~h}$ after stress stop (96hass). At this time point, the plants that had remained in the growth chamber were also measured, ensuring similarity in age in all plants. Plants in the field were measured in the early flowering period, corresponding to the developmental stage of the plants at the 96hass time-point measurements. The chlorophyll fluorescence data are presented as the ratio of variable to maximum fluorescence $(\mathrm{Fv} / \mathrm{Fm})$ or as the basal fluorescence level, $\mathrm{F}_{0}$ (for further information on these parameters, see Strasser et al, 2000).

\section{Data analysis}

All statistical analyses were made using the statistical software package SPSS for Windows (version 11.5) (SPSS Inc., Chicago, US). In all tests performed, the significance level used was $\alpha=0.05$. When data followed a normal distribution, comparisons were made using a $t$ test or a Univariate Analysis of Variance, including Post Hoc Tamhane or Tukey B test. Otherwise the nonparametric Mann-Whitney U test or the Kruskal-Wallis $\mathrm{H}$ test was used (SPSS base system and on-line guides).

\section{ACKNOWLEDGEMENTS}

We thank: Plant Genetic Systems for providing the transgenic oilseed rape material; Teis Nørgaard Mikkelsen for discussions on chlorophyll fluorescence; Dr. Nadia Al-Kaff for guiding on the microarray experiment; Bente Andersen, Liselotte Meltofte and Lis Brandt for their great technical assistance; The Danish Research Agency (Centre of Bioethics and Risk assessment) for funding this study.

Received March 4, 2005; accepted July 4, 2005. 


\section{REFERENCES}

Angadi SV, Cutforth HW, Miller PR, McConkey BC, Entz MH, Brandt SA, Volkmar KM (2000) Response of three Brassica species to high temperature stress during reproductive growth. Can. J. Plant. Sci. 80: 693-701

Arnold ML (1997) Natural Hybridization and Evolution. Oxford University Press, New York, Oxford.

Arnold ML, Hodges SA (1995) Are natural hybrids fit or unfit relative to their parents? Trends Ecol. Evol. 10: 67-71

Arntz MA, DeLucia EH, Jordan N (1998) Contribution of photosynthetic rate to growth and reproduction in Amaranthus hybridus. Oecologia 117: 323-330

Arntz MA, DeLucia EH, Jordan N (2000) From fluorescence to fitness: variation in photosynthetic rate affects fecundity and survivorship. Ecology 81: 2567-2576

Broer I (1996) Stress inactivation of foreign genes in transgenic plants. Field Crop Res. 45: 19-25

Chèvre AM, Ammitzbøll H, Breckling B, Dietz-Pfeilstetter A., Eber F, Fargue A, César Gomez-Campo C, Jenczewski E, Jørgensen RB, Lavigne C, Meier MS, den Nijs H, Pascher K, Seguin-Swartz G, Sweet J, Stewart Jr. CN, Warwick S (2004) A review on interspecific gene flow from oilseed rape to wild relatives. In: den Nijs HCM, Bartsch D, Sweet J, eds, Introgression from genetically modified plants into wild relatives, CABI publishing, Oxfordshire, pp 235 251

DEFRA (1999) The hybrid oilseed rape system. http:// www.defra.gov.uk/environment/gm/regulation/pgs/03.htm

Down RE, Ford L, Bedford SJ, Gatehouse LN, Newell C, Gatehouse JA, Gatehouse AMR (2001) Influence of plant development and environment on transgene expression in potato and consequences for insect resistance. Transgenic Res. 10: 223-236

Ellstrand NC (2003) Dangerous liaisons? : when cultivated plants mate with their wild relatives. The John Hopkins University Press, Baltimore and London

Gulden RH, Shirtliffe SJ, Thomas AG (2003) Harvest losses of canola (Brassica napus) cause large seedbank inputs. Weed Sci. 51: 83-86

Hansen LB, Siegismund HR, Jørgensen RB (2001) Introgression between oilseed rape (Brassica napus L.) and its weedy relative $B$. rapa L. in a natural population. Genet. Resour. Crop Ev. 48: 621-627

Hansen LB, Siegismund HR, Jørgensen RB (2003) Progressive introgression between Brassica napus (oilseed rape) and B. rapa. Heredity 91: 276-283

Hauser TP, Shaw RG, Østergård H (1998a) Fitness of F1 hybrids between weedy Brassica rapa and oilseed rape ( $B$. napus). Heredity 81: 429-435

Hauser TP, Jørgensen RB, Østergård H (1998b) Fitness of backcross and F2 hybrids between weedy Brassica rapa and oilseed rape (B. napus). Heredity 81: 436-443

Havaux M (1993) Characterization of thermal damage to the photosynthetic electron transport system in potato leaves. Plant Sci. 94: 19-33
James C (2004) Preview: Global status of commercialised transgenic crops: 2004. ISAAA Briefs No 32, Ithaca, NY

Jørgensen RB, Andersen B (1994) Spontaneous hybridization between oilseed rape (Brassica napus) and weedy $B$. campestris (Brassicaceae): a risk of growing genetically modified oilseed rape. Am. J. Bot. 81: 1620-1626

Krause GH, Weis E (1984) Chlorophyll fluorescence as a tool in plant physiology. II. Interpretaion of fluorescence signals. Photosynth. Res. 5: 139-157

Külheim C, Ågren J, Jansson S (2002) Rapid regulation of light harvesting and plant fitness in the field. Science 297: 9193

Landbo L, Jørgensen RB (1997) Seed germination in weedy Brassica campestris and its hybrids with $B$. napus: Implications for risk assessment of transgenic oilseed rape. Euphytica 97: 209-216

Mariani C, DeBeukeleer M, DeBlock N, Goldberg RD (1990) Introduction of male sterility into plants by a chimaeric ribonuclease gene. Nature 347: 737-741

Mariani C, Gossele V, DeBeuckeleer M, DeBlock M, Goldberg RB, DeGreef W, Leemans J (1992) A chimeric ribonuclease-inhibitor gene restores fertility to male sterile plants. Nature 357: 384-387

Meyer P, Linn F, Heidmann I, Meyer H, Niedenhof I, Saedler H (1992) Endogenous and environmental factors influence $35 \mathrm{~S}$ promoter methylation of a maize A1 gene construct in transgenic petunia and its colour phenotype. Mol. Gen. Genet. 231: 345-352

Meza TH, Kamfjord D, Håkelien AM, Evans I, Godager LH, Mandal A, Jakobsen KS, Aalen RB (2001) The frequency of silencing in Arabidopsis thaliana varies highly between progeny of siblings and can be influenced by environmental factors. Transgenic Res. 10: 53-67

Misra AN, Srivastava A, Strasser RJ (2001) Fast chlorophyll a fluorescence kinetic analysis for the assessment of temperature and light effects: a sliding model for stress recovery phenomena. 12th Int. Congress of Photosynthesis, Brisbane

Morrison MJ (1993) Heat stress during reproduction in summer rape. Can. J. Bot. 71: 303-308

Muller PY, Janovjak H, Miserez AR, Dobbie Z (2002) Processing of gene expression data generated by quantitative real-Time RT-PCR. BioTechniques 32: 1372-1379

Neumann K, Dröge-Laser W, Köhne S, Broer I (1997) Heat treatment results in a loss of transgene-encoded activities in several tobacco lines. Plant Physiol. 115: 939-947

Price JS, Hobson RN, Neale MA, Bruce DM (1996) Seed losses in commercial harvesting of oilseed rape. J. Agr. Eng. Res. 65: 138-191

Rieger MA, Lamond M, Preston C, Powles SB, Roush RT (2002) Pollen-mediated movement of herbicide resistance between commercial canola fields. Science 296: 2386-2388

Rieseberg LH (1997) Hybrid origins of plant species. Аnnu. Rev. Ecol. Syst. 28: 359-589 


\section{H. Ammitzbøll et al.}

Snow AA (2002) Transgenic crops - why gene flow matters. Nat. Biotechnol. 20: 542

Snow AA, Andersen B, Jørgensen RB (1999) Cost of transgenic herbicide resistance introgressed from Brassica napus into weedy B. rapa. Mol. Ecol. 8: 605-615

Strasser RJ, Srivastava A, Tsimili-Michael M (2000) The fluorescence transient as a tool to characterize and screen photosynthetic samples. In: Yunus M, Pathre U, Mohanty P, eds, Probing photosynthesis: mechanisms, regulation and adaptation, Taylor \& Francis, London, GB, pp 445-483

Thompson CE, Squire G, Mackay GR, Bradshaw JE, Crawford J, Ramsay G (1999) Regional patterns of gene flow and its consequence for GM oilseed rape. BCPC Symposium proceedings No 72: Gene Flow and Agriculture: Relevance for Transgenic Crops, pp 95-100
Yamane Y, Kashino Y, Koike H, Satoh K (1997) Increases in the fluorescence Fo level and reversible inhibition of photosytem II reaction center by high-temperature treatments in higher plants. Photosynth. Res. 52: 57-64

Young LW, Wilen RW, Bonham-Smith PC (2004) High temperature stress of Brassica napus during flowering reduces micro- and megagametophyte fertility, induces fruit abortion, and dirsrupts seed production. J. Exp. Bot. 55: 485495

Zhu B, Lawrence JR, Warwick SI, Mason P, Braun L, Halfhill MD, Stewart CN (2004) Stable Bacillus thuringiensis $(\mathrm{Bt})$ toxin content in interspecific $\mathrm{F}_{1}$ and backcross populations of wild Brassica rapa after Bt gene transfer. Mol. Ecol. 13: 237 